\title{
OPTIMUM VIRTUAL ENVIRONMENT FOR SOLVING COGNITIVE TASKS BY INDIVIDUALS WITH AUTISM SPECTRUM DISORDERS: THE QUESTIONS AND METHODS OF DESIGN
}

\begin{abstract}
Dr. Tatiana Yurievna Bystrova, Cultural Studies and Design Department, Ural Federal University, Russian Federation

E-mail: taby27@yandex.ru

Dr. Ludmila Valerievna Tokarskaya, Psychological Department, Ural Federal University, Russian Federation E-mail: liydmil@mail.ru

Dr. Darko B.Vuković, Russian State Social University (RGSU), Faculty of Economics, Moscow \&

Perm National Research Polytechnic University, Perm, Russian Federation

E-mail: vdarko@hotmail.rs

A R T I C L E I N F O

Original Research

Received: December, 23.2018.

Revised: March, 28.2019.

Accepted: April, 01.2019.

doi:10.5937/ijcrsee1901063B

UDK

159.922.072-056.34

616.89-008.48

Keywords:

cognitive tasks,

virtual reality,

virtual environment,

the phenomenon of presence,

immersion phenomenon,

autism spectrum disorders.

A B S T R A C T

The number of people with autism spectrum disorders (ASDs) is growing in Russia and the world at large. It is important to find ways to diagnose and correct the work with such individuals. There is much evidence that children with ASDs often exhibit pronounced communicative difficulties, problems in establishing visual contact etc. Specialists working with this category of patients face serious difficulties in trying to find effective ways to interact with them. The use of virtual reality environments that have the necessary parameters, determined theoretically, experimentally, and practically, can mitigate these difficulties. The study has shown that, at present, there is much experience in the field of virtual reality application while working with children who have ASDs. Nevertheless, there are several unspecified issues. First, as far as the perception of virtual reality by people with ASDs are concerned, it is especially important to study them. Of much importance are the peculiarities of their states associated with virtual reality, while solving cognitive tasks during diagnostic and corrective work stage, as well as in obtaining education. It is necessary to choose the right methods of visualization and interaction in a virtual environment. The focal point of the article is to justify the project of creating a virtual reality for the diagnosis and socialization of individuals with ASDs, i.e., its structure, stages and methods. In addition, the work is of interest in connection with the research of the phenomenon of presence in virtual reality.
\end{abstract}

(C) 2019 IJCRSEE. All rights reserved.

\section{INTRODUCTION}

There is the growing body of literature which indicates that the number of people with autism spectrum disorders (ASDs) in Russia and the world currently stands at $1.5 \%$, and according to some data, one in 68 children

\section{Corresponding Author}

Dr. Tatiana Yurievna Bystrova, Cultural Studies and Design Department, Ural Federal University, Russian Federation, E-mail: taby27@yandex.ru

\section{c) $($ ) $\$$}

This work is licensed under a Creative Commons Attribution - NonCommercial - NoDerivs 4.0. The article is published with Open Access at www.ijcrsee.com suffers from these disorders (Kim Y. S., et al., 2011). The questions of their adequate diagnostics and the subsequent effective socialization, including inclusive educational process are of much importance. ASDs are the group of complex deficiencies in mental development, characterized by the violation of the ability to social interaction, communication, and inadequate stereotyped behavior. The peculiarities of individuals with ASDs include the violation of social contacts, difficulties in recognizing visual objects, the violation of verbal and nonverbal communication, etc.

By today, Russian Federation has created a system for determining the educational route of a child with ASDs. The system emerges from a comprehensive survey within 
the framework of psychological, medical and training commission (the PMTC). The body of specialists, i.e., a psychiatrist, a teacher-psychologist, a speech therapist, a social teacher, and a speech pathologist determine children's state of higher mental functions and speech. They also specify the degree of mastering knowledge, abilities and skills and provide recommendations which designate educational organization.

The traditional examination procedure of the PMTC usually lasts from one to one and a half hours. It includes the main stages which are as follows: the acquaintance with the child, the study of the documents, the health screening itself. At the final stage the commission body makes up conclusions, provide recommendations and fills out the standard form of experts' opinion report. The individual with ASDs, as a rule, does not have time to adapt to the new premises and people, to maintain productive contacts with them. This often leads to the fact that the child can show much lower results comparing with the familiar and / or more comfortable conditions for him.

One of the main objectives of the study is to clarify the specifics of cognitive tasks for individuals with ASDs. There is much evidence that in the clinical picture of specific cases of ASDs there are often signs of other kinds of mental developmental disability, most often accompanied by mental retardation (see Morozov S. A., Morozova T. I. and Beliavskii B. V., 2016). Interestingly, "nowadays there is no single point of view on the features of intellectual development of children with ASDs. Experts express different opinions which sometimes are opposite" (Morozov S. A., Morozova T. I. and Beliavskii B. V., 2016, p. 11). A key theoretical aspect of the research is to clarify this issue. The practical goal lies within the domain of the survey and the evaluation of results (Morozov S. A., Morozova T. I. and Beliavskii B. V., 2016).

Solving the problems of diagnosis and socialization of people with ASDs will allow the presentation of tasks in a specially created virtual environment. Our target is to determine the optimal parameters of this virtual environment. On the one hand, this virtual environment will help reduce the level of stress that traditionally arises during diagnostics, and, therefore, make it more accurate and effective. On the other hand, by changing the quality of the virtual environment, determining its optimal parameters in accordance with the peculiarities of perception and behavior of a specific child with ASDs, it is possible to achieve the faster and more profound learning of the material during the training process, as well as the formation of communication skills. Consequently, these actions correspond to the trends of modern inclusive education, which implies the individualization of educational trajectories when individuals with ASDs are included in the overall process of education and socialization.

\section{MATERIALS AND METHODS}

The presence effect can be studied using the methods which are as follows:

- A subjective method based on self-reporters or questionnaires. It provides a comparison between the parameters of two virtual environments among themselves or the parameters of the virtual environment compared with the real environment, etc.;

- A physiological method, with the help of which the presence of physiological reactions to the image of a dangerous environment is recorded. E.g., a view from a great height to the abyss. Presence is determined indirectly, through a reaction like that which would appear in the real world;

- A psychophysiological method, which serves to identify the features of the perception of virtual environment, as well as the nature of the influence of virtual media on the addressee: 1) test questionnaires for determining the profile of functional brain asymmetry (Arshavskii V. V., 1998; Nikolayeva E.I., 2003; Bragina N. N. and Dobrokhotova T. A., 1988). The definition of the situational emotional state with the help of M. Lusher's projective test; 2) a direct inquiry method; 3) instrumentation techniques, i.e., the analysis of perception with the help of the eye movement recording system (eye-tracker) RED500; a modified measurement technique for the description of human galvanic skin response by I. R. Tarkhanov, W. Ferre with the help of the professional computer polygraph «Diana»; electroencephalography (EEG) and event related potentials (ERP) analysis using the EEG-ERP-24/8 electro-encephalograph «Mitzar-EEG-ERP-24/8».

The application of psychophysiological methods makes it possible to objectify the data obtained, to determine the leading regions of the brain when solving cognitive tasks in normal people and in individuals with ASDs. These methods help consider the problem of integrating information in virtual reality in comparison with ordinary reality, including 
cases of virtual disease. The combination of oculography with EEG and virtual reality allows a comprehensive assessment of the processes of attention, visual perception, thinking in the experiment and in the ordinary environment among the individuals with ASDs and neurotypical users. It will also allow to model optimal learning environments through visualization.

- Behavioral, through which the presence is determined by the coincidence of behavioral responses of subjects with those that they would have in a similar situation in the real environment.

The experimental part of the study will be conducted on the basis of the brain laboratory and neurocognitive development of $\mathrm{UrFU}$ named after first President of Russia

\section{B. N. Yetsin.}

The sample will consist of two groups of subjects: the first will include individuals with autism spectrum disorders aged 18-25 years, numbering 20 people; the second group will include neurotypical individuals aged 18-25 years, also numbering 20 people. The experimental group will include only individuals with ASDs who have verbal communication skills, capable of providing answers to proposed cognitive tasks, as well as describing their states while in a virtual environment.

The choice of the age range is due, to the urgency and inadequacy of the issue of the education of persons with disabilities (HIA), and specifically with ASDs, in institutions of secondary and higher vocational education. In addition, the problem of vocational guidance and employment for this category of persons, and especially those with ASDs, is significant. At the same time, for teenagers with ASDs, preparation for work with the use of information technologies, including virtual environment tools, is of importance, so now there is already a positive experience of employment of people with ASDs, primarily in the IT sphere (e.g., SAP company, etc.).

\section{RESULTS}

Therefore, the main components of the proposed study aimed at the application of virtual reality for diagnosis and socialization of persons with ASDs will be as follows:

The stages of research

1. The design and development of special software tools and the study of cognitive functions of individuals with ASDs using virtual reality media.
2. The testing of a prototype adapted for people with ASDs, conducting experiments to detect the influence of the presence state on the solution of intellectual problems, both for ordinary users and for adolescents with ASDs.

During the study, it is planned to identify how virtual reality will be perceived by children with ASDs, e.g., neutral, as a pleasant experience, as a harmful experience, distracting from the performance of a cognitive task, or, as an experience, helping to focus on the cognitive task. It is also planned to clarify the specifics of the statements of individuals with ASDs in terms of their dictionary, the grammatical structure of their speech compared with neurotypical people.

Table 1. AR formats and children with ASD

\begin{tabular}{llc}
\hline \multicolumn{1}{c}{$\begin{array}{c}\text { Needs and } \\
\text { characteristics of } \\
\text { children with ASD }\end{array}$} & AR formats to meet the needs of the child \\
with ASD & $\begin{array}{c}\text { Hypothetical } \\
\text { relationship of } \\
\text { reality and AR, } \\
\text { providing } \\
\text { immersion } \\
\text { (requires } \\
\text { experimental } \\
\text { verification) }\end{array}$ \\
\hline $\begin{array}{l}\text { Communicative } \\
\text { difficulties }\end{array}$ & $\begin{array}{l}\text { Using an intermediary character for } \\
\text { communicating with other people; gamification } \\
\text { of communication }\end{array}$ & $50-50$ \\
\hline Pursuit of monotony & $\begin{array}{l}\text { Clarity of scenarios; reinforcement of repetitive } \\
\text { script elements with recognizable visual signs }\end{array}$ & $90-10$ \\
\hline $\begin{array}{l}\text { Concentration } \\
\text { problem }\end{array}$ & $\begin{array}{l}\text { The appearance of pop-up windows with visual } \\
\text { and audible reminders }\end{array}$ & $80-20$ \\
\hline Motor disorders & $\begin{array}{l}\text { Inclusion of small buttons in the most } \\
\text { interesting games or exercises }\end{array}$ & $90-10$ \\
\hline $\begin{array}{l}\text { Emotional } \\
\text { vulnerability }\end{array}$ & $\begin{array}{l}\text { Backgrounds and other colors that have a } \\
\text { positive impact }\end{array}$ & $80-20$ \\
\hline $\begin{array}{l}\text { The need for the right } \\
\text { behavior models }\end{array}$ & $\begin{array}{l}\text { Inclusion of models in scenarios of games } \\
\text { connecting reality and AR; social stories }\end{array}$ & $50-50$ \\
\hline
\end{tabular}

3 . The analysis of the specifics of perception of images and features of cognitive tasks by persons with ASDs in virtual reality.

4. The development of proposals on the specifics of the psychological and aesthetic parameters of the virtual environment used in the diagnosis and training of persons with ASDs.

5 . The modification of programs, the development of recommendations for designing a full-fledged environment for diagnosing and training individuals with ASDs using visualization tools, including virtual reality environments.

6. The development of proposals on technical, visual, psychophysiological and aesthetic parameters of the virtual environment for persons with ASDs, including the model of inclusive education. 


\section{DISCUSSIONS}

\subsection{The peculiar aspects of the mental development diagnostic of children with ASDs}

The work on the examination of children with ASDs should be aimed at maximizing the opportunities and abilities of such children for successful inclusion in the educational environment of the training organization. In this regard, PMTC specialists face several challenges which are as follows:

- the specification of the mental state of the child and his potential in terms of obtaining the most accessible education;

- the definition of an educational route which must be adequate to the identified individual characteristics;

- the psychological and educational counseling of parents or children's legal representatives, training, medical and social workers. If necessary, the counseling should also embrace the employees of other institutions and departments representing the interests of the child in the family, the educational organization, the society at large;

- the monitoring of the learning dynamics and the level of social adaptation to the process of including the child in the educational environment;

- the development and implementation of preventive and corrective-developmental activities regarding the child with ASDs;

- the educational activities targeting the improvement of the psychological, instructional and medico-social culture of specialists and teaching staff.

The main aspects of conducting indepth diagnostics highlight key points which are as follows:

- The complex, comprehensive and holistic-dynamic assessment of developmental disabilities, including the inclusion of medical, psychological, training, and social features and developmental parameters of the child. The comprehensiveness and integrity of the assessment should consist in the systematic approach to mental development. It must also encompass the understanding of the developmental laws and their closest correspondence to the definition of the necessary conditions for the child's adaptation. The assessment must target the maximum social self-realization of the child, specifically, within the educational environment. The dynamic aspect of the assessment suggests the interrelated analysis of the actual development of the child emerging from the anamnestic and follow-up data at different age stages, as well as the dynamics of changes of the child's state indicators directly during the process of the examination.

- The refinement and specification of peculiar educational conditions:

- The category of the adapted educational program (its content, level, focus, the degree of differentiation and individualization).

- The conditions for the implementation of the adapted educational program, i.e., the front-line teaching mode, an individual approach, a frontal individual method, as well as teaching at home. The conditions may also include mixed training which encompasses an individual mode of attending lessons, one or two or more days off per week in accordance with the evidence and in agreement with the administration of the educational institution. The conditions also include the features of introducing the child to the educational environment, i.e., the degree, volume and the form of inclusion.

The requirements for the procedure and methodological support of the diagnostic examination include a set of key aspects which are as follows:

1. The procedure and duration of the examination are determined by the age, individual and typological features of the child's development.

2. Parents must give written consent for a child examination.

3. It is desirable to conduct the child's examination in his / her usual environment, with the obligatory presence of parents.

The criteria for the adequacy of the procedure and the duration of the examination are as follows:

- a specialists' communicative contact with the child under examination;

- the availability, effectiveness, success of the child's activity in the survey process, considering the necessary assistance measures;

- the possibility of the "self-compensation" of the child's condition or, if necessary, the termination of the examination if there are severe psychosomatic, neurodynamic, neurotic, psychopathic or psychotic disorders during the examination;

- the parents or child's legal representatives' confidence in the examination specialists. The parents must be willing to accept specialists' conclusions and follow their recommendations. 
In the situation of conflicting opinions of specialists regarding the assessment of the child's condition and recommendations for the development of an adapted educational program, compromise solutions emerge. They target more favorable social conditions for the child. In these cases, we recommend the diagnostic periods of training, psychological, social, and legal support, as well as a dynamic observation in the process of repeated examinations. A child should be given a chance to use his backup capabilities.

It is necessary to note that the requirements should correspond to the methodological materials used during the assessment of psychological and training features of child development during the examination. First, there are requirements for the standard invariability of stimulant materials' techniques which are primarily visual. The main requirements for such diagnostic techniques are as follows:

- The methodology should have a sufficiently long period of approbation on modern children, including children with different types of deviant development;

- Its stimulus material should stay unchanged for a long time, as well as the technology of their presentation and the analysis of results;

- In connection with the need for an indepth examination, it is essential to use the methodology of a clinical approach. Consequently, the methodology determines the possibility of the flexible presentation of the stimulant material, i.e., it is desirable to use it during a training experiment. The latter makes it possible to assess such a nonspecific indicator as the child's learning ability;

- The methodology should have enough polyfunctionality, i.e., the ability to assess various indicators of the state and characteristics of the child's activity. At the same time the methodology should have a preferential orientation to certain parameters of a specific mental development sphere;

- The implementation of an age-based approach to the study of the child's mental development. The methodology should cover a sufficiently large age range. To achieve this goal its tasks should be designed as more complex. Simultaneously, the complexity of the methodology should cover several periods of childhood, e.g., from younger preschool to primary school age, etc.;

- The results obtained must have, first, qualitative, conditionally normative indicators that characterize modern children. For certain methods, quantitative indicators are possible.

There are special principles which determine the diagnostic activity of specialists. They are as follows:

1. The construction of an examination hypothesis based on the holistic view of the child. The hypothesis must encompass the knowledge of various branches of psychology, pediatrics, child psychiatry, medical genetics, education science, including special correctional pedagogy;

2. The complete use of the algorithm for changing the diagnostic hypothesis in the light of the data obtained (Bayes rule);

3 . The construction of the procedure or technology of the examination in accordance with the actual age and the peculiarities of the child's behavior. The procedure should correlate with the adult-child dyad;

4. The use of the methodical tools adequate to the goals and hypothesis of the examination, considering procedural features that allow obtaining multifactor (multifunctional) information due to the technology of presentation;

5. The analysis of the received data using the technologies of integrative results' evaluation, which gives the maximum information not only about the specifics of development and the formation of various functions and systems at the phenomeno-logical level, but also allows to identify the complex and hierarchy of reasons leading to this development option;

6. The categorization of the actual child's developmental level with an access to the type and structure of the development. At this level it is important to reach the formulation of the conclusion, the definition of the probabilistic forecast of the development, which, in turn, will allow to develop an effective program for accompanying the child.

The assessment of a child's mental development is presented in the form of the following stages, which follow one another:

1. Anamnesis;

2. The formulation of the hypothesis of the examination regarding preliminary conclusion, clarifying and adjusting it in the process of work;

3. The procedure for examining the child using appropriate tactics and technologies adequate to the age and capabilities of this category of deviant mental development;

4. The system analysis of survey results, their comparison in accordance with the hypothesis;

5. The final formulation of the conclu- 
sion, considering the results obtained. This stage includes the understanding of the mechanisms and ways that led to the observed features, the definition of a probabilistic forecast of development, the ways and methods of individual approach to the child, the methods and techniques of corrective-developing work.

Therefore, the assessment of the features of the ASDs child's mental development is designed to ensure adequate progress, education and upbringing in accordance with the identified features. This assessment has certain stages, it is provided with adequate tools, considering the child's age, and its characteristics. All these factors determine the design of the diagnostic procedure in virtual reality conditions.

\subsection{The basic concepts of design and research work on the creation of virtual reality for the completion of cognitive tasks}

Now we proceed to the definition of the terminological apparatus of work. It is an important stage, which ensures more effective interaction of specialists of various profiles. The main terms are as follows:

1. Virtual reality. This term denotes a special environment created by the computer with the help of special devices, i.e., a helmet, screens with illusion of three-dimensionality, etc. The created environment is perceived by a user as the real world in which he really is and does not observe it from the outside. The user interacts with it directly, the same way he interacts with the ordinary world. Virtual reality is an artificial environment that can detect the position and actions of users and replace or supplement the feedback they perceive, causing a person to sense a presence in the virtual world.

2. Virtual environment. The term "virtual environment" encompasses a specific computer visualization environment, which is created by special devices to solve a specific task. Experts outline specific characteristics of virtual environment which are as follows: a three-dimensional and often stereoscopic environment; the possibility of a view from within some space, the chance of immersion in the virtual world; the control over the visible part of the virtual environment; dynamism; a multisensory mode which provides information to several senses.

3. "The perceptual illusion of imme- diacy" or "the sense of being there". These features provide the phenomenon of presence, which is opposed to seeing the image from the outside. At the same time, when experiencing presence, the user "forgets" about the machines that supply him with the images. Presence is impossible without immersion, which, depending on the interaction of technical means, creates a virtual reality with the senses of man. Immersion results in the involvement, determined by the content of the environment with which the person is currently working, and what is happening in it.

4. Immersion. The term "immersion" traditionally refers to the submersion of a person in a computer-generated world. Experts distinguish visual, auditory, vestibular (used mainly for simulators and games) and less common tactile immersion, depending on the applied technology.

Immersion arises when, due to the quality of the interface, the stimuli acting on the senses of the user come not from the real world but are created by the computer. The immersion can be complete, incomplete or absent.

A virtual environment designed for full immersion technologies is called immersive, as opposed to a non-immersive environment in which the sense organs of the user are not cut off from the real-world stimuli. It is assumed that in an immersive virtual environment, the user can sense the effect of presence.

5. Involvement. It is a psychological state experienced as the consequence of focusing on a consistent set of incentives or reasonably related actions and events. Involvement depends on the value that a person gives to stimuli, actions or events and can appear in any environment, regarding the variety of activities or events.

\subsection{The development of ideas about virtual reality}

The concept of virtual reality appeared at the turn of the 1980s and $1990 \mathrm{~s}$, when software and hardware environments created for aviation training devices and simulators began to be used in various types of research, computer imaging, education, and games and entertainment.

In the $2^{\text {nd }}$ half of the $1990 \mathrm{~s}$, work is being done to exploit the possibilities of virtual reality in medicine and psychology. Virtual reality was suggested to be used to overcome various phobias and dependencies (see Strickland D., et al., 1997). In this case, virtual en- 
vironments had the relatively poor quality of graphics and interfaces, but a quick immersion into the virtual world and the presence of such states, like presence, allowed to receive interesting results.

At the same time, the first publications on the use of virtual reality in autism began to appear, although at first all results were limited to an analysis of the possibilities of virtual reality (Strickland D., 1997).

To date, there is a considerable body of literature describing the use of virtual reality to help people with ASDs (Averbukh V. L., et al., 2014; Wang M, Reid D., 2011; Lahiri U., et al., 2013; Kuriakose S., Lahiri U., 2015; Didehbani N., et al., 2016). In general, publications describe the methods of using virtual reality for children and adolescents with ASDs. In several papers, the results of experimental studies are presented, e.g., Wang M., Anagnostou E. (2014). They describe the use of natural interfaces within virtual reality environments. At the same time, it is necessary to note that there is the insufficient study of the imagery of visual objects, the limited goals set for developers and researchers.

Of much importance is the fact that the professor of Oxford University Steven Chance $(\mathrm{PhD})$ organized a research group "Neuroanatomy and Cognition Group" at the Department of Clinical Neurobiology. Their projects are devoted to the study of cognitive and psychiatric disorders and comparative evolutionary neurobiology. The group studies the interrelation of brain structures and functions: language and cognitive function (http:// chancelab.nden.ox.ac.uk/Publications.html).

As far as Russian studies of computer psychology are concerned, it is necessary to mention Lomonosov Moscow State University whose researchers use the virtual reality environment based on CAVE (Cave Automatic Virtual Environment). This activity encompasses the project "The Application of Virtual Reality Technologies in the Development of Innovative Methods for Studying Cognitive Processes of a Person" (2012-2013-https: // istina.msu.ru/projects/8824217/). This project is focused on the interdisciplinary research, including such areas as computer psychology (imaging and interface research), autism psychology and computer visualization, including graphic and web design tools. This can ensure the study of both psychological problems of autism research with the help of virtual reality environments, as well as the visualization component taken together with the interfaces corresponding to the tasks set.
Nowadays the design of an educational environment for children with autism spectrum disorders, including its content and design, is also under study. There is a body of literature describing the ethical aspects of work with ASDs children (see Bystrova T. Yu., Tokarskaja L.V., 2016; Bystrova T. Yu., Tokarskaja L.V, Grozina V.A., 2016).

In the context of the educational activity with ASDs students, there are publications describing the method of projects (Bystrova $\mathrm{T}$. Yu., Larionova V. A., 2015).

\subsection{The features of virtual reality designed for individuals with ASDs}

The work on the creation and use of virtual reality environments for the diagnosis and socialization of people with ASDs is interdisciplinary in nature. It emerges at the intersection of psychophysiology, cognitive sciences, mathematical modeling, virtual reality, special pedagogy and psychology.

In this paper, we can use the experience of developing specialized computer visualization systems, for which it is necessary to create new methods of displaying objects and interfaces. In this case, it is important to determine the individual characteristics of specific users who can adequately interpret the results of modeling and visualization. Therefore, the study will use the results of works on studying the features of perception and analysis of virtual reality, i.e., the presence and immersion state, as well as its possible negative consequences (cyber sickness) (Averbukh N. V., 2010), (Averbukh N., 2014), (Riva, G., Mantovani, F. 2012). In addition, it is planned to adapt and further use the software developed for conducting the relevant experiments.

It is planned to offer individuals with ASDs and neurotypical people the same cognitive tasks in the same environment to compare their states when solving the tasks. In the long term it will allow to achieve the results which are as follows: 1) diagnostically create a series of tasks in virtual reality for conducting complex psychological and pedagogical examination of people with suspicion of autism spectrum disorders; 2) during rehabilitation to formulate training assignments in obtaining education, vocational guidance, preparation for further employment.

The conditions for creating a virtual reality with the characteristics that contribute to the solution of cognitive tasks are as follows:

1. The evaluability of methods for 
studying the phenomenon of presence. Some of them already exist, the missing part must be found or transformed from existing ones considering the characteristics of people with ASDs.

2. The results of a comparative analysis of the presence status of individuals with ASDs and neurotypical people.

3. The data on the phenomena of presence and immersion in virtual reality environments, related to the state and cognitive abilities of people with ASDs.

4. The data on peculiar features of cognitive tasks' performance by people with ASDs in a virtual environment. These data must be compared with the results of performing similar tasks in a real environment.

5. The analysis of research results in the field of designing techniques aimed at diagnosing ASDs using virtual reality.

6 . The psychological and aesthetic parameters of the virtual environment used in the diagnosis and rehabilitation of people with ASDs.

7. The development of visualization techniques and human-computer interaction for virtual reality systems used in working with people with ASDs based on the activity approach to develop interactive visualization systems (Averbukh V. L., et al., 2014), and the re-quirements for maximum naturalness of interfaces (Starodubtsev I., et al., 2014).

These conditions determine the sequence of work on the project to create a virtual reality for the solution of cognitive tasks. On their basis, we conduct a sketch search, modeling, approbation and adjustment of virtual reality. They, in fact, represent the stages of interdisciplinary design and research activities.

\subsection{The risks of work on the use of virtual reality in dealing with per- sons with ASDs}

Starting to work on the design of a virtual environment for people with ASDs, it must be remembered that its influence is still not fully understood even regarding normatively developing individuals. For example, a study conducted by the Center for Children with $\mathrm{Au}$ tism in Romania showed that $90 \%$ of children aged 2-3 years had triggered the development of ASDs by over-viewing (more than 4-5 hours per day) of television programs or interaction with other forms and types of virtual reality (http://lib.komarovskiy.net/virtualnyj-autizm- eto-uzhe-realnost.html). Marius Zamfir, a psychologist and coordinator of the Center, introduced the term "virtual autism", pointing out that "it is practically impossible to distinguish between autism which has developed from the uncontrolled impact of the gadget on the child's psyche from the classical one". Among the manifestations of virtual autism there are specific features which are as follows: the lack or difficulty of socialization skills, the lack of persistent eye contact, speech disorders, difficulties with role-playing games, and the presence of stereotypes. M. Zamfir points out that "the difference between classical and virtual autism lies in the fact that in the first case we are talking about biological neurological underdevelopment, and in the second case about the destruction of neurodevelopment caused by the impact of virtual reality". This study does not consider the impact of virtual reality on children with ASDs, and does not outline other indicators, except for the time spent in a virtual environment. However, it is obvious that the impact of various gadgets and environments on the child may vary significantly. All this should be considered when designing a virtual environment.

\section{CONCLUSIONS}

During the study, the intellectual activity of adolescents with ASDs will be determined within the framework of virtual reality environments. We will reveal and describe the peculiarities of perception of virtual reality by adolescents with ASDs. We also target the experience of virtual reality phenomena in adolescents with ASDs.

Based on the results of the study, it is planned to develop methods for investigating ASDs using virtual reality media; the methods and software of the ASDs diagnostic process. Accordingly, we plan the implementation of prototypes of software for teaching people with ASDs using visual systems, including the ones based on virtual reality. We will determine necessary and sufficient optimal parameters of the virtual environment, which will facilitate the diagnosis and training of persons with ASDs. In addition, we will develop recommendations on the design of virtual reality environments for individuals with ASDs. Based on the results obtained, it is planned to design and test virtual reality, considering the characteristics of individuals with ASDs. In advance, it is assumed that it should be depleted of sensory stimuli, i.e., it should include a 
few colors, a few distractions, and soft colors primarily.

Therefore, from a fundamental point of view, the work will make a contribution to understanding the phenomenon of presence, including related physiological and psychophysiological states of inclusion in activities, and to develop an environment for diagnosis and training of persons with ASDs.

\section{ACKNOWLEDGEMENTS}

The work was supported by act 211 Government of the Russian Federation, contract № 02.A03.21.0006.

The work was supported by RFBR № 17-36-01100.

\section{Conflict of interests}

The authors declare no conflict of interest.

\section{REFERENCES}

Arshavskii, V. V. (1998). Mezhpolusharnaia asimmetriia $v$ sisteme poiskovoi aktivnosti [Interhemispheric asymmetry in the system of search activity]. Vladivostok.

Averbukh, N. (2014). Subjective-Situational Study of Presence. Lecture Notes in Computer Science, Proceedings of "Augmented and Mixed Reality. Designing and Developing Virtual and Augmented Environments" Conference. (issue 8525), pp: 131-138. https://doi.org/10.1007/978-3-31907458-0 13

Averbukh, N. V. (2010). Psikhologicheskie aspekty fenomena prisutstviia $\mathrm{V}$ virtualnoi srede. $V_{o}-$ prosy psikhologii [The Questions of Psychology], 5: 105-113.

Averbukh, V. L., Averbukh N. V., Naimushina A. V., Semenishchev D. V. and Tobolin D. I. (2014). Deiatelnostnyi podkhod pri proektirovanii cheloveko-kompiuternogo vzaimodeistviia na primere meditsinskikh interfeisov [The activity approach in the design of human-computer interaction: the example of medical interfaces]. M: Izdatelskaia gruppa URSS.

Bellani, M., Fornasari, L., Chittaro, L., \& Brambilla, P. (2011). Virtual reality in autism: state of the art. Epidemiology and psychiatric sciences, 20(3), 235-238. https://doi.org/10.1017/ S2045796011000448

Bragina, N. N. and Dobrokhotova T. A. (1988). Funktsionalnye asimmetrii cheloveka [Functional asymmetries in humans]. Meditsina.

Bystrova, T., \& Larionova, V. (2015). Use of virtual mind mapping to effectively organise the project activities of students at the university. ProcediaSocial and Behavioral Sciences, 214, 465-472. https://doi.org/10.1016/j.sbspro.2015.11.724

Bystrova, T. Y., Tokarskaja L. V. and Grozina V. A. (2016). Graphic desigh for individuals with autism spectrum disorders. Akademicheskij Vestnik
UralNIIproect RAASN, 2(29): 95-99.

Bystrova, T. Yu. and Tokarskaja L. V. (2016). Design of the educational environment for children with autism spectrum disorder: to the formulation of the question. Izvestia. Ural Federal University Journal. Series 1. Issues in education? Science and culture, 1(147): 168-175.

Chance S. Neuroanatomy and Cognition Group. http:// chancelab.nden.ox.ac.uk/Publications.html

Didehbani, N., Allen, T., Kandalaft, M., Krawczyk, D., \& Chapman, S. (2016). Virtual reality social cognition training for children with high functioning autism. Computers in Human Behavior, 62, 703-711. https://doi.org/10.1016/j. chb.2016.04.033

Kim, Y. S., Leventhal, B. L., Koh, Y. J., Fombonne, E., Laska, E., Lim, E. C., ... \& Song, D. H. (2011). Prevalence of autism spectrum disorders in a total population sample. American Journal of Psychiatry, 168(9), 904-912. https://doi. org/10.1176/appi.ajp.2011.10101532

Kuriakose, S., \& Lahiri, U. (2015). Understanding the psycho-physiological implications of interaction with a virtual reality-based system in adolescents with autism: a feasibility study. IEEE Transactions on Neural Systems and Rehabilitation Engineering, 23(4), 665-675. https://doi. org/10.1109/TNSRE.2015.2393891

Lahiri, U., Bekele, E., Dohrmann, E., Warren, Z., \& Sarkar, N. (2013). Design of a virtual reality based adaptive response technology for children with autism. IEEE Transactions on Neural Systems and Rehabilitation Engineering, 21(1), 55-64. https://doi.org/10.1109/TNSRE.2012.2218618

Morozov, S. A., Morozova T. I. and Beliavskii B. V. (2016). K voprosu ob umstvennoi otstalosti pri rasstroistvakh autisticheskogo spektra. Autizm $i$ narusheniia razvitiia [Autism and developmental disorders], 1(14): 9-18.

Nikolaeva, E. I. (2003). Psikhofiziologiia [Psychophysiology]. M: PER SE; Logos.

Proekt "Primenenie tekhnologii virtualnoi realnosti $v$ razrabotke innovatsionnykh metodov izucheniia kognitivnykh protsessov cheloveka (20122013)" [Project "Application of Virtual Reality Technologies in the Development of Innovative Methods for Studying Human Cognitive Processes (2012-2013)"'].

Riva, G., \& Mantovani, F. (2012). From the body to the tools and back: a general framework for presence in mediated interactions. Interacting with Computers, 24(4), 203-210. https://doi. org/10.1016/j.intcom.2012.04.007

Starodubtsev, I., Averbukh, V., Averbukh, N., \& Tobolin, D. (2014, June). Professional Natural Interfaces for Medicine Applications. In International Conference on Human-Computer Interaction (pp. 435-439). Springer, Cham. https://doi. org/10.1007/978-3-319-07854-0_76

Strickland, D. (1997). Virtual reality for the treatment of autism. Stud Health Technol Inform, 44: 81-6.

Strickland, D., Hodges, L., North, M., \& Weghorst, S. (1997). Overcoming phobias by virtual exposure. Communications of the ACM, 40(8), 34-40. https://www.researchgate.net/profile/ Larry_Hodges/publication/220420035_Overcoming Phobias by Virtual Exposure/ links/5470a7d30cf24 af340c0f2fa/OvercomingPhobias-by-Virtual-Exposure.pdf 
Virtualnyi autizm eto uzhe realnost [Virtual autism is already a reality]. Date Views 06.04.2018 http:// lib.komarovskiy.net/virtualnyj-autizm-etouzhe-realnost.html

Wang, M., \& Anagnostou, E. (2014). Virtual reality as treatment tool for children with autism. Comprehensive guide to autism, 2125-2141. https://doi. org/10.1007/978-1-4614-4788-7 130

Wang, M., \& Reid, D. (2011). Virtual reality in pediatric neurorehabilitation: attention deficit hyperactivity disorder, autism and cerebral palsy. Neuroepidemiology, 36(1), 2-18. https://doi. org/10.1159/000320847 